\title{
On the Improvement of College English Writing through Integration of Language Skills \\ Xiu Zeng
}

Foreign Language School, Nanchang Normal University, Nanchang, Jiangxi, 330032

2267395464@qq.com

Keywords: English writing; Integration; Language skills; Preparation

\begin{abstract}
English writing has long been viewed as a challenge to most Chinese students because of their weak language foundation, inadequate absorption of the language and less targeted practice for the production of satisfactory written work. Much attention has been directed to the low efficiency in the writing teaching. By adopting some widely used English-teaching approaches, this paper tries to explore a way to integrate writing into the whole process of English teaching with the other language skills serving as preparation for writing. The focus of this paper is put on the interrelation among the mutual-related language skills and the improvement in the efficiency of English writing teaching.
\end{abstract}

\section{Introduction}

Writing is not only one of the five basic language skills in language learning, it is also an important means of communication in social life. It is usually considered to be a sign of one's language competence. It can measure the learner's linguistic competence at different levels, including lexical competence, grammatical competence, textual competence and pragmatic competence. But writing, for the difficulties it involves in terms of language items, such difficulties as vocabulary, sentence structure, rhetoric, etc, may be ranked as the most challenging language skill for most language learners.

For most Chinese learners, English writing is still a big problem. Even students at university level suffer from a limited lexicon and weak language foundation though they work hard and do well in reading exam. Often they have difficulty expressing their ideas in proper English even when they are bursting with fountains of ideas. To get students out of the plight, to improve their writing ability and efficiency of writing teaching, here in this paper it is suggested that students be provided opportunities to involve writing in the whole process of English learning, ie, to take the class practice of listening, reading, speaking and translating as preparatory steps to the improvement of writing.

According to the modern FLT theories, the language learning process is the combination of input, intake (processing and memorizing in listening and reading) and output (speaking and writing). Two basic elements-- comprehension and production are always contained in English teaching, which can be regarded as two stages: input and output. FLT in China aims to cultivate students' language application based on enough comprehensible input material. Two objectives are usually to be desired in listening and reading classes: one is to improve comprehension through the comprehensible input; the other is to present usage of language for students to imitate in speaking and writing.

\section{A Research into the Causes of Students' Inadequacy in Writing}

For majority of Chinese students, English is a second language that is taken as a compulsory course in both high school and university. In spite of the fact that much time and efforts have been devoted to the learning in their secondary school, they still cannot make proper use of English to express themselves in university. Possibly I suppose the following may be the causes: 
First, many university students come from the provinces relatively backward in the development of economics and education, especially from the isolated areas in the countryside, where there is an urgent need for the qualified teachers of English, which greatly affects the English level of new students in universities.

Second, students have seldom been required to do real writing before entering university though they have studied English for six years in high school. Neither have they been trained with specific skills. Their writing requirement then was only the translation of sentences or paragraphs. As a result, they are generally considered to be unskilled writers.

Third, because of the limited number of hours allocated to the reproduction of English, either oral or written, they are unable to apply what they have learned to the daily communication.

Fourth, there is only a specially -designed writing course for a term which seems to be unrelated to any other courses of English.

Fifth, for the above-mentioned causes it is quite easy for students to give it up or put it to a position secondary to the other language skills. To get students out of such a condition, a series of writing-oriented classroom instructions and activities are much needed in order to prepare students for writing since students generally feel that writing is very difficult to improve on their own [1]. In this case, a teacher of English should make efficient use of the limited time in class and make good plans to integrate writing into the whole process of teaching, with listening, reading, translating and speaking activities serving as preparations for writing. This is what this paper mainly concerns.

\section{Integrated Practice of the Language Skills}

Listening Practice. Listening is an essential part of language input to students. Listening activities, if organized well, can not only help students review the previously-learned words and consolidate newly-learned ones but also provide them with rich sources of writing materials, for the same or related theme in each unit of a textbook goes through every part of the unit with many synonyms repeated and related ideas developed. Further progress can be made by trying paralleled text, modified versions of the text with different details. Besides course-book CD and cassette, other listening materials can also be introduced to students after class to familiarize them with a variety of topics and give food to thought for later writing. Such a constant exposure to different language materials can improve students' listening comprehension on the one hand, and facilitate students' effective assimilation of new language into their existing cognitive structure on the other hand.

A teacher's standard English is also a source of listening material. His /her proficiency in command of English should be a professional obligation [2]. An English teacher himself has to be qualified enough to have acquired grammatically-correct, precisely-chosen English so that his English can be taken as a valuable and effective input to his students. He is expected to use English most of the time either in explanation of listening or reading material or in talk with students in speaking class, thus establishing English as the main classroom language. He may choose simple English for elementary classes and complex English for intermediate or advanced ones. In this way, his students can be constantly exposed to much communicative use of English. As Krashen (1985) postulates in his Input Hypothesis that the command of language is acquired through prolonged exposure to the language and through comprehensive input from others in the language environment [3]. According to Krashen, an important condition for language acquisition is that the learner understands (through hearing and reading) input language that contains structure a bit beyond his current level of competence. In other words, teachers' expressions should be just far enough beyond students' current competence that they can understand most of it but is still challenged to make progress. By absorbing and imitating, students will gradually develop an instinct for the ways English is actually used and then students can be expected to put the language obtained from teachers to use in oral or written work.

Text Reading. Reading, as one of the essential skills of communication, has long been recognized to play a significant role in the overall acquisition of any language, the same is true of its role in the development of students' writing ability. As Gebhard (1996) pointed out that the 
useful things in writing are word choice, use of appropriate grammar, syntax, mechanics and organization of ideas into a coherent and cohesive form [4]. "In both in-school and out of school context, reading and writing serve as integral processes in learning new information, in translating information, for making sense of new ideas and for communicating thoes new ideas with others"[5]. It is chiefly through reading process that students can accumulate vocabulary, build solid language foundation and grow familiar with the organization of an essay, all of which makes the completion of a piece of good writing possible.

In terms of linguistic competence, poor command of vocabulary and inability to use it properly may be one of the major obstacles in the preparation for written work for Chinese college students . Vocabulary is often more important and challenging than grammar in that vocabulary is very infinite and words are often more complex than they appear to be, for words are not isolated from but associated with a certain type of context or situation [6]. thus they behave differently in different context. Therefore, special attention has to be directed to the meaning and usage of words and expressions in classroom reading.

Further, it is important to recognize that students do not learn from the first presentation of the new language items alone. They need to be introduced or even reintroduced to the new items until they can have a full command of what they have learnt and produce them automatically when required. To reach this goal, students are often asked to practise a certain number of language models, sentence patterns or simply word substitution. Almost in any English textbooks, there is always such an item of exercise "rewrite the following sentences after the models" or " replace A with B", etc. The repeated phrases and structures are usually the most often used and idiomatic ones. They often add color and vividness to the expression of our ideas and feelings. To be familiar with them is really a great advantage to students when they are going to make a speech or fulfill a written work.

In the course of text reading, teachers can not be much satisfied that students have understood what words convey to them. We should go further to ask students to explore what is hidden under the lines, what is most instructive and enlightening to them. After class, mind-improving books will be introduced as a supplementary reading task to push back their horizon and enrich their inner world, for these readings are treasure of learning and a rich source of human civilization, from which young students can constantly learn beauty, wisdom and life, A student writer nurtured with such education is expected to create a piece of compelling work.

Sentence or Paragraph Translating. There are generally two major types of written exercises divided as "vocabulary" and "grammar" in each reading unit. Translation exercise is included in "vocabulary" item. To translate sentences into English is intended to practise certain target words and sentence structures that appear in the text. It is more difficult than simply filling in blanks, or replacement of words, for it is a test on one's understanding of the words and correct use of grammatical patterns, it can promote a free use of language in later task of composition though there is no sense of communication, no sense of authenticity in it.

More challenging is the translation of a paragraph which is usually a summary of the text or a parallel text. It can be fulfilled only when students have a full comprehension of the main points of the text and only when they know how ideas are organized and developed through different and complex sentence structures. But its advantage is that students have one more chance to relearn and practise both old and new language which could otherwise be misinterpreted or forgotten. This part of exercise cannot be left out, for it has the function of a bridge to join different parts of a unit. It is a revision of what has been learnt and it is an introduction to what will be carried out.

This stage of practice marks a half-way between language input and communicative output. To some degree, it is less communicative because of the attempt to ensure that certain specific language is used [7]. However, it is important in helping students assimilate facts about new language and in enabling them to produce the new language for the first time.

Speaking Activities. Speaking, like writing, has been regarded as an important means of language production, a means of communication Here I am not dwelling on its general function in human communication, but only on its specific role as an introductory stage to writing. Judged 
from the types of speaking tasks, the activities purposefully designed in class are, in a sense, the controlled or semi-controlled ones.

For example, after a detailed study of texts, students finally come to deal with certain learning tasks where students are required to take a combined practice of speaking and writing. Often it is organized as follows: students are divided into small groups to discuss the questions in English, most of the questions are connected with the theme of the text. Group activities sometimes vary depending on the type of the text, so speech contest, role play and mock debate are often brought to classroom as an alternative to group discussion. After the discussion or play, they are required to write an article on the basis of their discussion with the questions serving as a framework.

From this arrangement of classroom activities, we can expect that writing can be facilitated to some degree when preceded by theme-related oral activities. In this way, students are less likely to be short of language and supporting details needed in expressing themselves. Another equally important point is that this arrangement is in agreement with the principle of process writing approach that group prewriting discussion is introduced as an important component of writing instruction. In the process, students can make up for each other's deficiencies, learn from each other and meet each other's needs. As Ann Ramie's (1983) put it "For second language learners, who need more time and opportunity to using the language with others, group work is especially beneficial"'[8].

\section{Conclusion}

To sum up, learning to write is a long, complex and creative process in which a series of language skill practice and the related activities are involved and interrelated [9]. On the one hand, practice of every other skill helps to bring about improvement in writing proficiency. On the other hand, improvement of writing contributes much to the development of the other language skills [10]. Therefore, writing practice, like the practice of the other skills, is a part of language learning and a part of quality-oriented education. If a teacher of English has a deep understanding of the interrelation between writing and the contributing factors, integrates writing into the whole process of teaching, then all the efforts made by teachers and students will be much rewarded.

\section{References}

[1] L.L. Qin: Journal of China English Language Educational Association, (2004), No.5, p. 83-86.

[2] Paul Davies. (2002). Success In English Teaching [M]. Shanghai: Shanghai Foreign Language Education.

[3] Krash, S.(1985). The Input Hypothesis: Issues and Implication. London and New York: Longman.

[4] J.G. Gebhard: Teaching English as a Foreign or Second Language (The University of Michigan Press, 1996).

[5] Mulcainy-ernt.P and Stewavt.J. Writing and Reading in integrated language Arts: Ibid. 1994.

[6] Laflamme and John G: Journal of Adolescent \& Adult Literacy, Vol. 40, 1997, No.5, p.372-384.

[7] Jeremy Harmer. (1983). The Practice of English Language Teaching [M]. New York: Longman.

[8] Raimes, A: Techniques in Teaching Writing(Oxford University Press, 1983).

[9] L.M. Yang: New College English (Shanghai Foreign Language Education Press, 2002).

[10]Q.S. Chen: Teaching English in China, 2005, No.4, p.107-110. 